Check for updates

Cite this: RSC Adv., 2018, 8, 36951

Received 12th August 2018

Accepted 8th October 2018

DOI: 10.1039/c8ra06726k

rsc.li/rsc-advances

\title{
Dissolving organic matter from low-organic sewage sludge for shortening the anaerobic digestion time $\uparrow$
}

\author{
Yiyong $\mathrm{Li}^{\text {ab }}$ Yongyou Hu, (D)*cd Guofu Huang, ${ }^{\text {ef }}$ Ziqi Yu, $^{\mathrm{cd}}$ Wei $\mathrm{Bi}^{\mathrm{cd}}{ }^{\mathrm{cd}} \mathrm{HaO} \mathrm{Fan}^{\mathrm{cd}}$ \\ and Jianjun Du ${ }^{a b}$
}

Pretreatments have been successfully used to shorten the HRT of anaerobic digestion (AD) of sewage sludge, but they become ineffective for low-organic sewage sludge, with HRT > 10 days. Herein, a new process using alkaline hydrolysis-anaerobic digestion has been developed to solve this problem. Firstly, maximum organic matter in the sludge was dissolved by strong alkaline hydrolysis $(\mathrm{pH}>11)$ in a twostage alkaline hydrolysis system (TSAHS). Secondly, only the supernatant of the sludge that contained most of the methane potential was applied for AD. The operational conditions were optimized and the process mechanism was also analyzed. The results showed that under optimum operational conditions, above $19 \%$ of the organic matter in the sludge was released into the supernatant after alkaline hydrolysis in TSAHS, and the supernatant for AD achieved a methane production of $392 \mathrm{~mL} \mathrm{CH}_{4}$ per g COD. The process attained a methane production of $0.26 \mathrm{~m}^{3} \mathrm{CH}_{4}$ per $\mathrm{kg}$ VS and a VS reduction of $43.5 \%$, while the HRT was only $12 \mathrm{~h}$. The advantage of the mechanism was that the alkaline neutralization capacity of the sludge maintained a proper $\mathrm{pH}$ value for the supernatant from TSAHS, which benefited subsequent AD. It is concluded that the new process based on the dissolution of organic matter can attain a short digestion time for low-organic sludge.

\section{Introduction}

Sewage sludge discharged from wastewater treatment plants (WWTPs) has become a worldwide problem due to the large output and secondary pollution risk. ${ }^{1}$ In 2015, approximately 39.73 million tons of sewage sludge ( $80 \%$ moisture content) was generated in China. ${ }^{2}$ Huge amounts of human, physical and financial resources have been dedicated to sewage sludge disposal, and it has become clear that resource utilization of sewage sludge is an inevitable requirement. Value-added

${ }^{a}$ College of Environment Science and Engineering, Zhongkai University of Agriculture and Engineering, Guangzhou, Guangdong 510225, China

${ }^{b}$ Guangdong Provincial Engineering and Technology Research Center for Agricultural Land Pollution Prevention and Control, Guangzhou 510225, China

${ }^{c}$ Ministry of Education Key Laboratory of Pollution Control and Ecological Remediation for Industrial Agglomeration Area, College of Environment and Energy, South China University of Technology, No. 382, East Waihuan Road, Guangzhou Higher Education Mega Center, Guangzhou 510006, China. E-mail: yueguangzhuying@126.com; Tel: +8613602746125

${ }^{d}$ State Key Lab of Pulp and Paper Engineering, College of Light Industry and Food Science, South China University of Technology, Guangzhou 510640, China

${ }^{e}$ School of Chemical and Environmental Engineering, Weifang University of Science and Technology, Shouguang, 262700, China

${ }^{f}$ Shandong Peninsula Engineering Research Center of Comprehensive Brine Utilization, Shouguang 262700, China

$\dagger$ Electronic supplementary information (ESI) available. See DOI: 10.1039/c8ra06726k products and biomass energy can be reclaimed; the latter has received preferential attention for the sake of sanitation safety and energy demand. Anaerobic digestion (AD) is widely used for energy reclamation from sewage sludge. Nevertheless, the main disadvantage of $\mathrm{AD}$ is its long digestion time with a hydraulic retention time (HRT) of more than 20 days resulting in a heavy investment burden for reactor, space, etc. ${ }^{3}$ Limited hydrolysis of hard biodegradable cells and extracellular biopolymers in the sewage sludge are accused for the slow release of organic matters from the sewage sludge. ${ }^{4}$ Therefore, researchers tried to accelerate the release of organic matter using pretreatments to shorten the HRT. ${ }^{5}$ Shin and Kang ${ }^{6}$ adopted an electron beam with an irradiation dose of $6 \mathrm{kGy}$ for sewage sludge pretreatment, and the HRT for AD was decreased from 20 days to 10 days. Toreci et al. ${ }^{7}$ applied microwave $\left(175^{\circ} \mathrm{C}\right)$ for sewage sludge pretreatment in mesophilic anaerobic digesters, indicating a reduction of the HRT from 20 days to 10 days. A combined method of ultrasonication-ozonation $\left(9 \mathrm{~kJ} \mathrm{~g}^{-1}\right.$ TS and $0.012 \mathrm{~g}$ $\mathrm{O}_{3}$ per $\mathrm{g}$ TS) for sewage sludge pretreatment was also investigated, and the HRT was shortened from 20 days to 10 days. $^{8}$ Furthermore, a combination of high-pressure homogenization and alkaline conditions ( $\mathrm{pH} 10$ and 12000 psi pressure) minimized the HRT from 18 days to 13 days and was successfully applied in the WWTPs of Chilliwack, Canada and in the WWTP of Los Angeles County, California. ${ }^{9}$ The HRT has been 
successfully shortened to approximately 10 days by the pretreatments.

However, these pretreatment methods become ineffective for the $\mathrm{AD}$ of low-organic sludge (with a ratio of volatile solids/total solids (VS/TS) below 50\% that differs from the typical sludge in a range of $60-80 \%$ ), owing to the fact that the release of organic matters from low organic sludge is more difficult than that with high organic content. ${ }^{\mathbf{4} 10,11}$ For example, Feng et al. ${ }^{12}$ pretreated the low-organic sludge at pH 10 for $4 \mathrm{~h}$, and the HRT for AD was only reduced from 20 days to 15 days. Thermal pretreatment $\left(50-120^{\circ} \mathrm{C}\right)$ of low-organic sludge produced a similar result. ${ }^{10} \mathrm{It}$ can be seen that pretreatment alone is not enough to cope with the long HRT for AD of the low-organic sludge, as indicated by the HRT of much more than 10 days. ${ }^{11}$ Unfortunately, more and more low-organic sludge is being produced in recent years due to the increasing application of biological nutrient removal process in WWTPs. ${ }^{\mathbf{1 0 , 1 3}}$ At present, the average ratio of VS/TS of sewage sludge in China is only about $40 \% .{ }^{14}$ Hence, there is an urgent requirement to improve the pretreatment of the loworganic sludge.

It is noteworthy that a large degree of organic substances can be released from the sewage sludge by strong alkaline hydrolysis ( $\mathrm{pH}>11$, as a significant factor; the higher, the better), achieving a SCOD/TCOD ratio of up to $75 \%$ depending on the powerful ionization and hydrolysis reactions. ${ }^{15,16}$ In this case, we have assumed that $\mathrm{AD}$ only needs to be conducted with the supernatant of the low-organic sludge after sufficient alkaline hydrolysis so that most of the methane potential can be reclaimed. More importantly, the HRT can be greatly shortened because the supernatant practically has no rate-limiting step as that of hydrolysis by excluding the undissolved organic matters through centrifugation. To our knowledge, no researchers have proposed this idea, let alone its realization.

However, the problem of strong alkaline hydrolysis is the correspondingly high $\mathrm{pH}$ value of the supernatant beyond the $\mathrm{pH}$ limit for $\mathrm{AD}$; thus, acid neutralization is usually needed before $\mathrm{AD},{ }^{17}$ causing additional operation processes and chemical consumption. In our previous study, we have designed a two-stage alkaline hydrolysis system (TSAHS) to solve this problem. In TSAHS, $\mathrm{pH}$ of the effluent supernatant can be controlled below 10.0, even when the $\mathrm{pH}$ during alkaline hydrolysis is as high as $13.0 .^{18}$ And we also found that the effluent supernatant with $\mathrm{pH}<10.0$ is suitable for AD. On the basis of this study, a new process of alkaline hydrolysisanaerobic digestion is proposed to manage the low-organic sludge. Firstly, organic matter in the sludge, such as the proteinaceous matter with high methane potential, are maximally released into the supernatant by strong alkaline hydrolysis; secondly, only the supernatant that obtained most of the methane potential of the sludge is subjected to AD. The operational conditions of the process have been optimized and the process mechanism is also discussed. Based on the results, feasibility of the new process for shortening the AD time of the low-organic sewage sludge was confirmed.

\section{Materials and methods}

\subsection{Sludge samples}

Low-organic sewage sludge was obtained from the secondary sedimentation tank of Lijiao WWTP located in Guangzhou city, China. The sludge was sieved (mesh size $1.0 \mathrm{~mm}$ ) to remove sand and waste materials, gravitationally concentrated, and stored at $4{ }^{\circ} \mathrm{C}$. The concentrated sludge was diluted with distilled water to obtain a sludge sample of $20 \mathrm{~g} \mathrm{~L}^{-1}$. The sludge sample had VS/TS ratio of $48 \% \pm 2 \%$, TCOD of $11600 \pm$ $4300 \mathrm{mg} \mathrm{L}^{-1}$, SCOD of $29 \pm 10 \mathrm{mg} \mathrm{L}^{-1}$, TP of $225 \pm 25 \mathrm{mg} \mathrm{L}^{-1}$, $\mathrm{TN}$ of $850 \pm 80 \mathrm{mg} \mathrm{L} \mathrm{L}^{-1}$, water content of $98.2 \% \pm 0.2 \%$, and a $\mathrm{pH}$ value of $6.6 \pm 0.2$.

Anaerobic granular sludge (AGS) as seed sludge was obtained from an EGSB reactor at a distillery WWTP in Foshan city, China. The TS, VS, and $\mathrm{pH}$ values of the AGS were $29.3 \mathrm{~g} \mathrm{~L}^{-1}$, $22.0 \mathrm{~g} \mathrm{~L}^{-1}$, and $7.0 \mathrm{~g} \mathrm{~L}^{-1}$, respectively. The AGS was stored at $4{ }^{\circ} \mathrm{C}$ and resuscitated in a biochemical incubator $\left(35^{\circ} \mathrm{C}\right)$ for 7 days before inoculation. This inoculum was active and adaptable for $\mathrm{AD}$.

\subsection{Alkaline hydrolysis}

Alkaline hydrolysis was carried out in a TSAHS, as reported in our previous study. ${ }^{18}$ The lab scale TSAHS is shown in Fig. 1. For a start-up, $X_{3} \mathrm{~mL}$ of the sludge sample was injected into reactor A and $\mathrm{NaOH}$ solution $\left(10 \mathrm{~mol} \mathrm{~L}^{-1}\right)$ was added to attain an initial

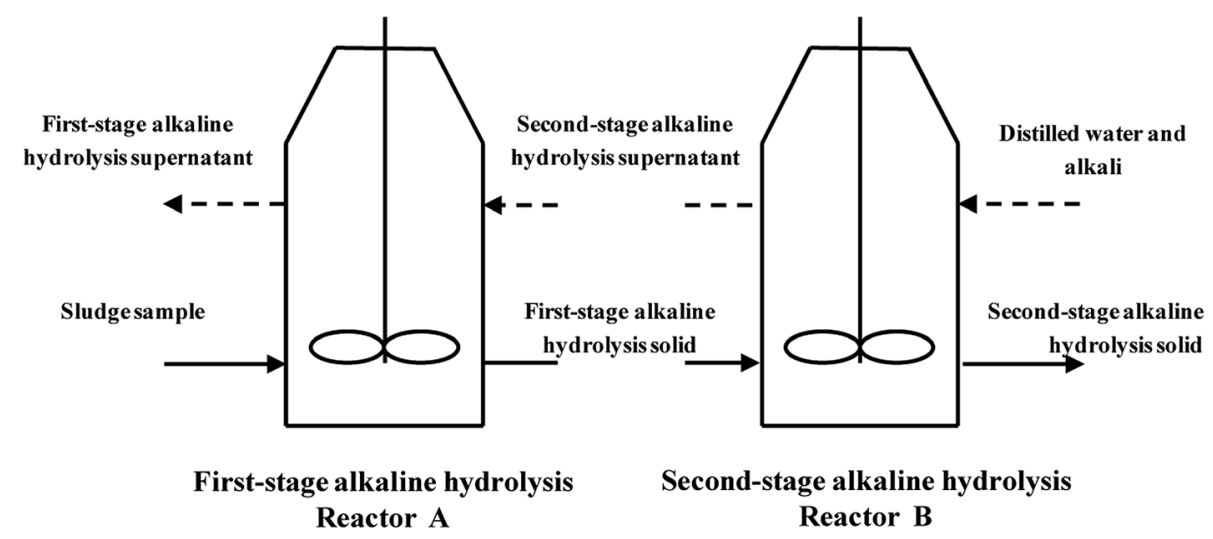

Fig. 1 Scheme of the two-stage alkaline hydrolysis system. 
$\mathrm{pH}$ of 10 under continuous stirring at $150 \mathrm{rpm}$, in which the optimized hydrolysis time is $1 \mathrm{~h}$ as reported in our previous studies. ${ }^{18,19}$ After $1 \mathrm{~h}$, the mixture was centrifuged at $4000 \mathrm{rpm}$ for $10 \mathrm{~min}$, and the first-stage alkaline hydrolysis supernatant was discharged. The residual solid from reactor A was injected into reactor $\mathrm{B}$, and $X_{2} \mathrm{~mL}$ of distilled water was injected. $\mathrm{NaOH}$ solution was then added to achieve an initial $\mathrm{pH}$ value of $X_{1}$ under constant stirring at $150 \mathrm{rpm}$. After $1 \mathrm{~h}$, the mixture was centrifuged at the same conditions and the second-stage alkaline hydrolysis supernatant was injected into reactor A, while the residual solid was discharged from reactor $B$. For the running phase, no $\mathrm{NaOH}$ was needed in reactor $\mathrm{A}$ to adjust the $\mathrm{pH}$, and the other operating procedures were the same as those of the start-up. Each sludge sample injection was referred to as one batch, and the supernatant discharged from reactor A (called effluent supernatant) was collected for methane production. The effluent supernatant was analyzed for COD, SCOD, $\mathrm{BOD}_{5}, \mathrm{TP}, \mathrm{TN}, \mathrm{NH}_{4}{ }^{+}-\mathrm{N}$ and $\mathrm{pH}$. The VS of the discharged solid from reactor $\mathrm{B}$ was also analyzed to assess the methane production using the new process.

In TSAHS, efficiency of the alkaline hydrolysis (EAH) indicates the dissolution degree of organic matter from the sewage sludge. The EAH and effluent supernatant $\mathrm{pH}$ were determined mainly by three factors: alkaline hydrolysis $\mathrm{pH}\left(X_{1}\right)$, distilled water volume $\left(X_{2}\right)$, and sludge sample volume $\left(X_{3}\right)$. Based on response surface method (RSM), an experiment with the three factors at three levels was conducted to determine the suitable operational conditions for TSAHS. The independent variables were $X_{1}, X_{2}$, and $X_{3}$, which were coded with $-1,0$, and +1 representing low, middle, and high levels, respectively. The response values were $Y_{1}(\mathrm{EAH})$ and $Y_{2}$ (effluent supernatant $\mathrm{pH}$ ). The data were analyzed by Design-Expert software to discover the interaction among these factors and predict the range of operational conditions that can achieve both high EAH and effluent supernatant $\mathrm{pH}$ of 9.0-10.0. The design of factors and levels is shown in Table 1. Each set of conditions for TSAHS was operated in three batches. The calculated mode of EAH is

$$
\mathrm{EAH}=\left(\mathrm{SCOD}_{\text {effluent }}-\mathrm{SCOD}_{0}\right) /\left(\mathrm{TCOD}-\mathrm{SCOD}_{0}\right)
$$

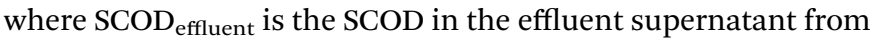
TSAHS, $\mathrm{SCOD}_{0}$ is the SCOD of the sludge sample, and TCOD is the total chemical oxygen demand of the sludge sample (in $\mathrm{mg}$ ).

\subsection{Anaerobic digestion}

The suitable operational conditions for $\mathrm{AD}$ were explored by biological methane potential test. The effects of the effluent supernatant $\mathrm{pH}$ value $(7.0,7.5,8.0,9.0$, and 9.9 adjusted by $\mathrm{HCl})$ and inoculum ratio $(10 \%, 20 \%, 30 \%, 40 \%$, and $50 \%$ in volume) on methane production were examined. Each treatment had three repetitions.

A $250 \mathrm{~mL}$ flask was filled with the effluent supernatant and seed sludge, flushed with $\mathrm{N}_{2}$ gas for approximately $2 \mathrm{~min}$, and immediately sealed with a rubber stopper. The control test (a fermentation flask filled with only the inoculum) was conducted to discount the methane production from the remaining organic matter in the inoculum. The flasks were incubated in
Table 1 Response surface method experiment for the two-stage alkaline hydrolysis system: $X_{1}$-alkaline hydrolysis $\mathrm{pH}, X_{2}$-distilled water volume, $X_{3}$-sludge sample volume, $Y_{1}$-EAH, and $Y_{2}$-effluent supernatant $\mathrm{pH}$

\begin{tabular}{llllrr}
\hline Run & $X_{1}$ & $X_{2}(\mathrm{~mL})$ & $X_{3}(\mathrm{~mL})$ & $Y_{1}(\%)$ & \multicolumn{1}{c}{$Y_{2}$} \\
\hline 1 & 13.00 & 10.00 & 25.00 & 8.84 & 9.09 \\
2 & 12.25 & 20.00 & 25.00 & 8.53 & 8.93 \\
3 & 12.25 & 20.00 & 25.00 & 8.12 & 8.83 \\
4 & 13.00 & 20.00 & 35.00 & 17.43 & 9.72 \\
5 & 13.00 & 30.00 & 25.00 & 30.09 & 11.68 \\
6 & 13.00 & 20.00 & 15.00 & 32.87 & 12.44 \\
7 & 12.25 & 10.00 & 15.00 & 7.98 & 8.99 \\
8 & 11.50 & 10.00 & 25.00 & 5.82 & 8.00 \\
9 & 11.50 & 30.00 & 25.00 & 9.53 & 7.83 \\
10 & 12.25 & 30.00 & 15.00 & 11.42 & 8.95 \\
11 & 12.25 & 20.00 & 25.00 & 11.55 & 8.49 \\
12 & 11.50 & 20.00 & 35.00 & 6.93 & 7.57 \\
13 & 12.25 & 20.00 & 25.00 & 11.13 & 8.41 \\
14 & 12.25 & 30.00 & 35.00 & 9.02 & 8.31 \\
15 & 11.50 & 20.00 & 15.00 & 9.93 & 7.99 \\
16 & 12.25 & 10.00 & 35.00 & 8.03 & 7.89 \\
17 & 12.25 & 20.00 & 25.00 & 9.60 & 8.48 \\
& & & & &
\end{tabular}

a biochemical incubator at $35{ }^{\circ} \mathrm{C}$ with manual shaking twice a day. The biogas production was measured by water displacement method, where the water was a $\mathrm{NaCl}$ saturated solution with $2 \mathrm{~mol} \mathrm{~L}^{-1} \mathrm{NaOH}$, and the methane content in the biogas was detected by gas chromatography method. ${ }^{20}$ Each day, a sample of $2 \mathrm{~mL}$ was taken from the flask using sterile disposable syringe and centrifuged at $4000 \mathrm{rpm}$. The centrifuged supernatant was analyzed for COD, volatile fatty acids (VFA), and pH. Methane yield was reported as the amount of methane generated per gram of COD added $\left(\mathrm{mL} \mathrm{CH}_{4}\right.$ per $\mathrm{g}$ COD) and as the amount of methane generated per kilogram of VS reduction $\left(\mathrm{m}^{3} \mathrm{CH}_{4}\right.$ per $\mathrm{kg}$ VS) for convenient comparison with traditional $\mathrm{AD}$.

\subsection{Analytical methods}

A PHS-3C was used for $\mathrm{pH}$ detection. The $\mathrm{COD}, \mathrm{BOD}_{5}, \mathrm{TP}, \mathrm{TN}$, and $\mathrm{NH}_{4}{ }^{+}-\mathrm{N}$ were determined according to standard methods. ${ }^{21}$ VS and VFA were tested by classic gravimetric method and titrimetric method, respectively. ${ }^{22}$ All the experiments were conducted at least in duplicate, and the average value is reported for all data. Additionally, statistical analyses were carried out using the Design-Expert software (version 7.1.6, Stat-Ease, Inc., Minneapolis, MN).

\section{Results and discussion}

\subsection{Alkaline hydrolysis of sewage sludge}

3.1.1 Optimization of operational conditions for the twostage alkaline hydrolysis system. In TSAHS, reactor A is mainly for $\mathrm{pH}$ adjustment and control, where the high $\mathrm{pH}$ value of the second-stage alkaline hydrolysis supernatant is decreased by dilution and alkaline neutralization capacity of the sludge sample, aiming at a pH value of 9.0-10.0; reactor B is mainly for alkaline hydrolysis, where the $\mathrm{pH}$ value is kept high enough for further release of organic substances from the first-stage 
alkaline hydrolysis solids, directed at achieving a high EAH. These goals are realized by RSM with the Design-Expert software 7.1.3.

(1) Establishment of the prediction model. Results from the Design-Expert software analysis suggested that a quadratic model was suitable for $Y_{1}$ and $Y_{2}$, with equations of

$$
\begin{aligned}
Y_{1} & =1544.69-258.83 X_{1}-6.03 X_{2}+4.10 X_{3}+0.58 X_{1} X_{2} \\
& -0.41 X_{1} X_{3}+10.90 X_{1}^{2}-0.02 X_{2}^{2}+0.02 X_{3}^{2} \\
Y_{2} & =174.38-28.86 X_{1}-1.05 X_{2}+0.81 X_{3}+0.09 X_{1} X_{2} \\
& -0.08 X_{1} X_{3}+1.26 X_{1}^{2}
\end{aligned}
$$

where $Y_{1}(\%)$ is the EAH, $Y_{2}$ is the effluent supernatant $\mathrm{pH}, X_{1}$ is the alkaline hydrolysis $\mathrm{pH}, X_{2}$ is the water volume $(\mathrm{mL})$, and $X_{3}$ is the sludge sample volume $(\mathrm{mL})$.

The results of the variance analysis are shown in Table S1. $\dagger F$ values of the two models (6.81 and 15.29) and the extremely low $p$ values (0.0096 and 0.0008) implied that the models fitted significantly. The determination coefficients $R^{2}$ of 0.8975 and 0.9516 indicated that less than $11 \%$ and $5 \%$ of the changes could not be explained, respectively, which also implied significant models. Therefore, the models could predict the experimental results.

(2) Effect of parameters. The perturbation plots manifest the effect of each parameter on the response values. A flatter curve suggests an insignificant effect, while a steeper curve suggests a significant effect. As seen in Fig. $\mathrm{S} 1, \uparrow X_{1}$ had a significant effect on $Y_{1}$ and $Y_{2}, X_{2}$ did not have a significant effect on $Y_{1}$ or $Y_{2}$, and $X_{3}$ did not have a significant effect on $Y_{1}$ but had a significant effect on $Y_{2} . X_{1}$ at a high level $(+1)$ was excellent for organic matter dissolution, and thus $X_{1}$ with a high level was better. An increase of $X_{3}$ could decrease $Y_{2}$ but could not create a clear decrease for $Y_{1}$; thus, $X_{3}$ with a high level was better. Additionally, $X_{2}$ at a mid-level could obtain balanced $Y_{1}$ and $Y_{2}$.

The three-dimensional surface response plot (Fig. S2 $\dagger$ ) presents the effects of $X_{1}$ and $X_{3}$ on the response values when $X_{2}$ was maintained at a mid-level. It was evident that an increase of $X_{1}$ could significantly increase $Y_{1}$ as well as $Y_{2}$. Hence, aiming at achieving both high EAH and an appropriate effluent supernatant $\mathrm{pH}$ of 9.0-10.0, an optimal region would be necessary.

(3) Determination and confirmation of optimum parameters. A cross-section was attained from the overlap of the contour plots by setting values from multiple responses. This cross-section was the optimal region that met the set values of the multiple responses and was shown by shadow graph, in which the range of optimal conditions could be directly observed. Fig. 2 shows the range of optimal conditions that met the set values of EAH > $12 \%$ and an effluent supernatant $\mathrm{pH}$ of $9-10$, where $X_{2}$ was set at mid-level.

An additional experiment applying the optimum conditions $\left(X_{1}=12.87, X_{2}=30.00 \mathrm{~mL}, X_{3}=35.00 \mathrm{~mL}\right)$ was conducted to confirm the effectiveness of these models. Experimental values of $19.03 \%$ and 9.9 were obtained for $Y_{1}$ and $Y_{2}$, which were close to the model values of $19.62 \%$ and 10.00 , respectively, with standard deviations below $5.0 \%$. These results demonstrated that the experiment designed by

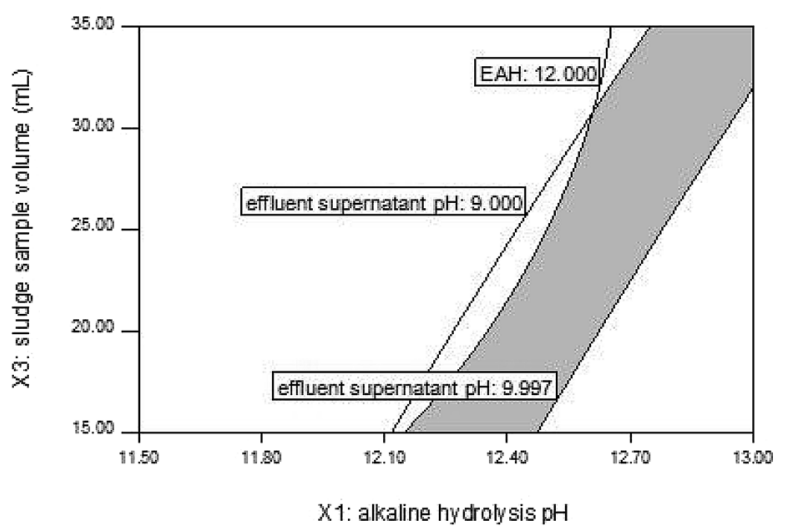

Fig. 2 Overlay plot for optimum EAH and effluent supernatant $\mathrm{pH}$.

RSM was reliable and that the models possessed a high predictive ability.

3.1.2 Evaluation of stability of the two-stage alkaline hydrolysis system. Sixteen batch operations were conducted under the optimum parameters to treat $2.8 \mathrm{~L}$ of the sludge sample (56 g dry sludge). $\mathrm{NaOH}$ consumption and effluent supernatant $\mathrm{pH}$ were recorded for each batch, and the SCOD of the effluent supernatant was analyzed intermittently. The stability of TSAHS was evaluated according to these parameters. As seen in Fig. 3 , there was a high dose of $\mathrm{NaOH}(1780 \mu \mathrm{L})$ at the start-up (batch numbered zero), which led to low $\mathrm{NaOH}$ consumption in batches $1-3$. The $\mathrm{NaOH}$ consumption fluctuated in the first 6 batches and stabilized in the next batches. The effluent supernatant $\mathrm{pH}$ was relatively stable at $9.9 \pm 0.1$ because of the acid-base neutralization capacity of the sludge. ${ }^{23}$ The SCOD also tended towards stability after batch 6 . Hence, TSAHS became stable after batch 6 .

3.1.3 Efficiency of the two-stage alkaline hydrolysis system. The mixed effluent supernatants of TSAHS from 16 batches had a total volume of $3.8 \mathrm{~L}$, and the parameters of the mixed effluent supernatants are shown in Table 2. The SCOD/TCOD ratio was $26 \%$ for the sludge samples in the 16 batches $(2.8 \mathrm{~L})$. It excelled the optimization result of $19 \%$ in the Section 3.1.1, but was far

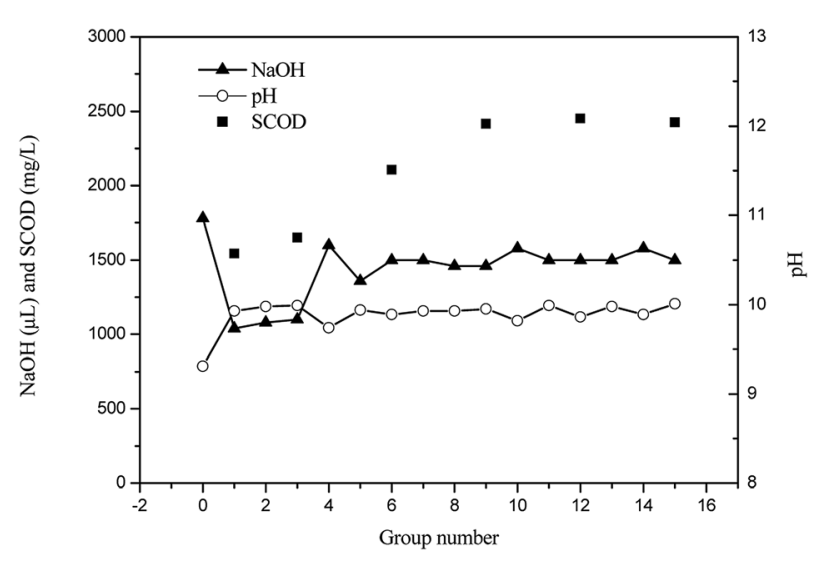

Fig. $3 \mathrm{SCOD}$ and $\mathrm{pH}$ of the effluent supernatant and $\mathrm{NaOH}$ consumption for each batch in the two-stage alkaline hydrolysis system. 
Table 2 Parameters of the effluent supernatant and discharged solid of the two-stage alkaline hydrolysis system

Effluent

supernatant

Discharged solid

$\begin{array}{llll}\text { COD } & 2649 \mathrm{mg} \mathrm{L}^{-1} & \text { VS reduction } & 43.5 \% \\ \text { SCOD } & 2213 \mathrm{mg} \mathrm{L}^{-1} & \text { Water content } & 86.8 \% \\ \text { BOD }_{5} & 1245 \mathrm{mg} \mathrm{L}^{-1} & \mathrm{pH} & 12.5 \\ \mathrm{TP} & 70 \mathrm{mg} \mathrm{L}^{-1} & & \\ \mathrm{TN} & 195 \mathrm{mg} \mathrm{L}^{-1} & & \\ \mathrm{NH}_{4}{ }^{+}-\mathrm{N} & 49.5 \mathrm{mg} \mathrm{L}^{-1} & & \\ \mathrm{pH} & 9.9 & & \end{array}$

from the SCOD/TCOD ratio of $75 \%$ reported in the literatures. ${ }^{15,16}$ This can be ascribed to the low organic matter in the sludge sample. Feng et al. ${ }^{12}$ also observed a SCOD/TCOD ratio of only $14.7 \%$ after alkaline pretreatment of this type of loworganic sludge. The effluent supernatant $\mathrm{pH}$ of 9.9 indicated that TSAHS could prevent a high $\mathrm{pH}$ value for alkaline hydrolysis. For the direct $\mathrm{AD}$ of the effluent supernatant, this control requirement was necessary. ${ }^{\mathbf{1 7}}$ As expected, it can be seen that the SCOD/COD was $83.5 \%$ for the effluent supernatant, suggesting the significant removal of undissolved organic matter. Additionally, the $\mathrm{BOD}_{5} / \mathrm{COD}$ value of 0.47 implied excellent biodegradability of the effluent supernatant, and the BOD : TN : TP value of $16.6: 2.6: 1$ suggested the presence of adequate nutrition in the effluent supernatant for $\mathrm{AD}$.

The discharged solid from the TSAHS after 16 batches had a VS reduction from $40.7 \%$ to $44.3 \%$, increase in water content from $85.8 \%$ to $89.6 \%$, and an increase in $\mathrm{pH}$ value from 12.3 to 12.5. Their average values are shown in Table 2 . The discharged solid (mainly recalcitrant fiber and mineral salt with less odour) is preferable for the usage in compost ${ }^{24}$ and biochar. ${ }^{25}$

\subsection{Anaerobic digestion of the effluent supernatant for methane production}

3.2.1 Optimization of operational conditions for anaerobic digestion

(1) Effect of effluent supernatant $p H$ on methane production. Fig. 4a shows a statistical analysis (Kruskall-Wallis test) carried out using the Statistical Package for Social Sciences software (SPSS 17.0, Inc., Chicago, IL, USA). The results $(\mathrm{K}-\mathrm{W}=36.75, p>$ 0.05 ) indicate that there were no significant differences among the five test groups for methane production, and the effluent supernatant $\mathrm{pH}$ had no significant effect on the methane production. A high methane production value of $331 \pm 5 \mathrm{~mL} \mathrm{~g}^{-1}$ COD was attained after a $\mathrm{pH}$ adjustment to 8.0 from the initial $\mathrm{pH}$ of 7.5 in the flask. In the batch $\mathrm{AD}$ of alkali-pretreated sludge, Li et al. ${ }^{17}$ also observed that an initial pH of 7.6 was more suitable for methane production. It is well known that alkalescency ( $\mathrm{pH}$ 7.0-7.6) benefits AD because of the metabolic balance between acid-producing bacteria and methanogens. There was methane production in the beginning of $\mathrm{AD}$ even at a high effluent supernatant $\mathrm{pH}$ of 9.9, indicating that methane production was not delayed. One reason for this result is that the initial $\mathrm{pH}$ of the flask was still low $(\mathrm{pH}=7.8 \pm 0.2)$, which
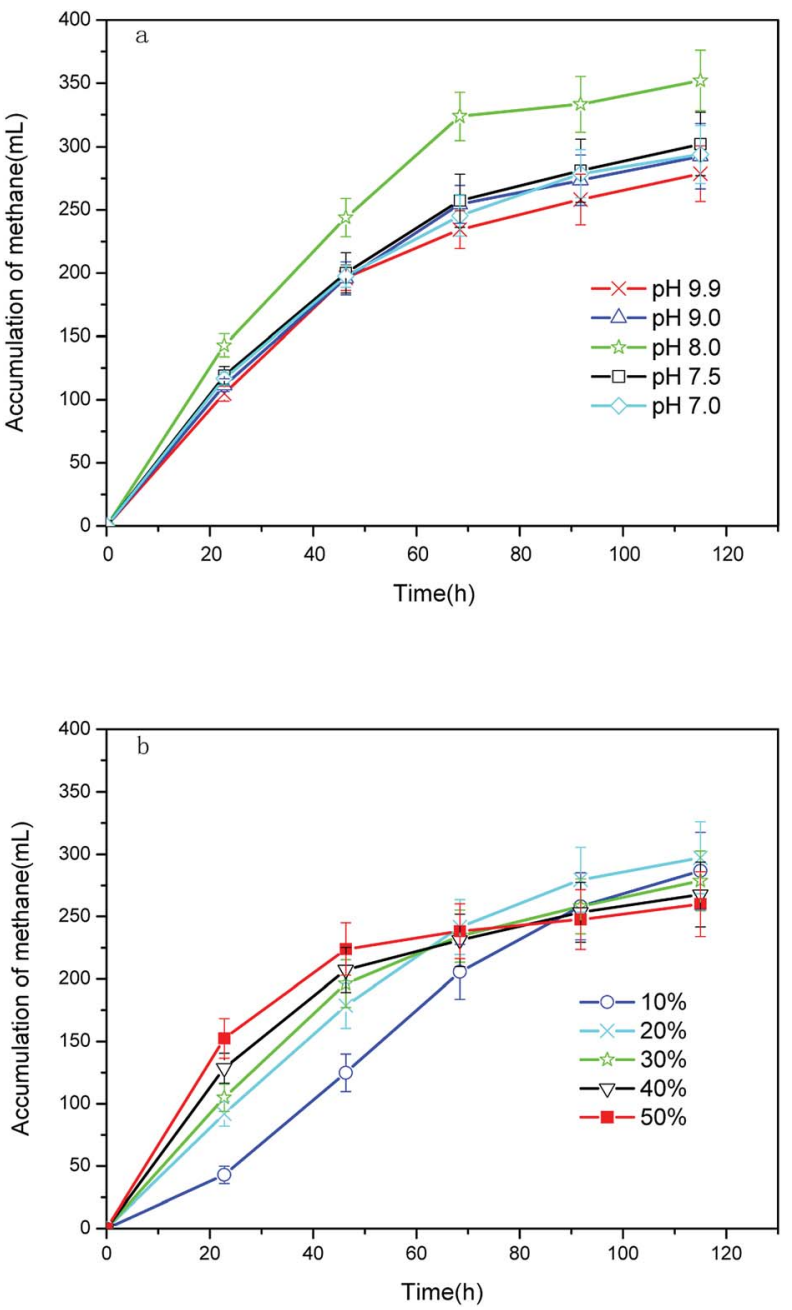

Fig. 4 Cumulative methane yield with different (a) effluent supernatant $\mathrm{pH}$ values and (b) inoculum ratios.

can be attributed to the dilution effect and acid-base neutralization capacity of the AGS. ${ }^{17}$ Another reason is that the effluent supernatant was easily biodegraded (with $30.9 \%$ COD removal within $24 \mathrm{~h}$ ), leading to a quick pH decrease from $7.8 \pm 0.2$ to $6.9 \pm 0.1$. Notably, methane production under the tested $\mathrm{pH}$ conditions approached its peak values at $72 \mathrm{~h}$, which revealed the high rate of methane production.

(2) Effect of inoculum ratio on methane production. The cumulative methane production decreased from $295 \pm 18 \mathrm{~mL}$ to $268 \pm 16 \mathrm{~mL}$ with increase in the inoculum ratio (Fig. 4b). This was ascribed to the minimization of organic matter in the effluent supernatant. Additionally, remarkably high methane production rates were obtained at higher inoculum ratios in the first $48 \mathrm{~h}$. It is believed that a lower food/microorganism ratio (identical to a higher inoculum ratio) is less toxic. ${ }^{26}$ A total of $85 \%$ of the methane was produced in the first $24 \mathrm{~h}$ at an inoculum ratio of $50 \%$, indicating a much shorter HRT under higher inoculum ratios.

3.2.2 Evaluation of anaerobic digestion of effluent supernatant for methane production. The mixed effluent supernatant (pH 9.9) was directly used for $\mathrm{AD}$ without a $\mathrm{pH}$ adjustment at an 
inoculum ratio of $60 \%$ and HRT of $12 \mathrm{~h}$. Three parallel experiments were conducted in flasks with a volume of $1000 \mathrm{~mL}$, and the results were reported as their average. The same experiment with the inoculum ratio of $50 \%$ and HRT of $24 \mathrm{~h}$ (based on Section 3.2.1) was also performed. Meanwhile, the sludge sample was also used for $\mathrm{AD}$ to test and verify the assumption that most of the methane potential could be reclaimed through the supernatant. For the inoculum ratio of $60 \%$ and HRT of $12 \mathrm{~h}$, the results showed that the methane yield for the supernatant was $392 \pm 2 \mathrm{~mL} \mathrm{CH}_{4}$ per g COD. It approached the theoretical value of $395 \mathrm{~mL} \mathrm{CH}_{4}$ per $\mathrm{g} \mathrm{COD}$ at $35^{\circ} \mathrm{C}$ and $1 \mathrm{~atm} .{ }^{27}$ The COD removal rate reached $90.6 \%$, indicating easy digestion of organic matter in the effluent supernatant. Based on the calculation of VS reduction during the process, the methane yield was $0.26 \mathrm{~m}^{3} \mathrm{CH}_{4}$ per $\mathrm{kg}$ VS. As expected, it amounted to $86.7 \%$ of the methane yield for the sludge sample $\left(0.30 \mathrm{~m}^{3} \mathrm{CH}_{4}\right.$ per $\mathrm{kg}$ VS with HRT of 20 days), demonstrating the validity of our assumption. Additionally, for the inoculum ratio of $50 \%$ and HRT of $24 \mathrm{~h}$, the methane yield was close to $392 \pm 2 \mathrm{~mL} \mathrm{CH}_{4}$ per $\mathrm{g}$ COD, but required twice as much time. Hence, the inoculum ratio of $60 \%$ and HRT of $12 \mathrm{~h}$ was suggested.

Other researchers reported that methane yields were 0.30 , 0.40 and $0.52 \mathrm{~m}^{3} \mathrm{CH}_{4}$ per $\mathrm{kg}$ VS for ultrasound, alkaline, and thermal + alkaline pretreatment methods with HRTs of 20, 9 and 21 days, respectively. ${ }^{28-30}$ Their methane yields (VS/TS $=$ $79 \%$ ) are much higher than those obtained in our study, which can be ascribed to a low methane conversion in the sludge sample with low organic content used in our study (VS/TS = $48 \%$ ). Feng et al. ${ }^{12}$ and Yan et al. ${ }^{10}$ also had methane yields below $0.15 \mathrm{~m}^{3} \mathrm{CH}_{4}$ per $\mathrm{kg}$ VS for this type of sewage sludge (VS/ $\mathrm{TS}=38 \%$ ). However, the HRT in our study was only $12 \mathrm{~h}$, which is much shorter than the above HRTs. Therefore, the objective of designing the new process has been achieved.

\subsection{Discovery of the process mechanism}

3.3.1 $\mathrm{pH}$ adjustment mechanism for the alkaline hydrolysis system. Sewage sludge contained organic substances with acidic groups (such as carboxyl and phenolic groups) and a carbonate buffer system, ${ }^{31-33}$ providing alkaline neutralization capacity for the sewage sludge. Hence, the model of alkaline neutralization for sewage sludge was designed by fitting the titration curve. The curve was drawn according to the method described by Zhu et al. ${ }^{23}$ In simple terms, a sludge sample of $50 \mathrm{~mL}$ was placed in a beaker, stirred with a magnetic stirrer and titrated with $1 \mathrm{~mol} \mathrm{~L}^{-1} \mathrm{NaOH}$, and the $\mathrm{pH}$ of sludge sample was monitored. The result is shown in Fig. S3.†

A regression equation was built from multiple regression analysis, and both the quadratic and cubic curves fit the experimental data well. The quadratic equation was chosen because of considerations regarding model conciseness. The quadratic equation is

$$
y=7.832+0.006 x-1.573 \times 10^{-6} x^{2}, R^{2}=0.970 .
$$

Here, $y$ is the $\mathrm{pH}$ and $x$ (mmol $\mathrm{NaOH}$ per kg dry sludge) is the alkaline dose. The alkaline neutralization capacity for sewage sludges at various $\mathrm{pH}$ values could be predicted by this model.
As an example, $x$ was 425.506 when $y=10.0$. In other words, each kilogram of dry sludge can neutralize $425.506 \mathrm{mmol} \mathrm{NaOH}$ when $\mathrm{pH}$ of the sludge sample is adjusted to 10.0. Thus, the sludge sample possessed considerable alkaline neutralization capacity, which is beneficial for $\mathrm{pH}$ adjustment.

3.3.2 Mechanism of anaerobic digestion of effluent supernatant for high-rate methane production. VFA plays an important role in $\mathrm{AD}$. To discover the mechanism for the high-rate methane production from the effluent supernatant with $\mathrm{pH}$ 9.9, VFA changes and $\mathrm{pH}$ were monitored during $\mathrm{AD}$ to understand the close relationship between the VFA concentration and the $\mathrm{pH}$ value.

As seen in Fig. 5a, the VFA production was fast and achieved a relatively high level within $20 \mathrm{~h}$, demonstrating the super biodegradability of the effluent supernatant. However, VFA degraded rapidly after it was produced, without accumulating in the effluent supernatant with $\mathrm{pH} 9.9$ and inoculum ratio of $50 \%$. Meanwhile, the VFA accumulation was distinct for an effluent supernatant $\mathrm{pH}$ of 9.9 and an inoculum ratio of $10 \%$, achieving a high concentration of $338 \mathrm{mg} \mathrm{L}^{-1}$. The accumulation was reflected by the fast decrease of $\mathrm{pH}$ from 8.64 to 7.41
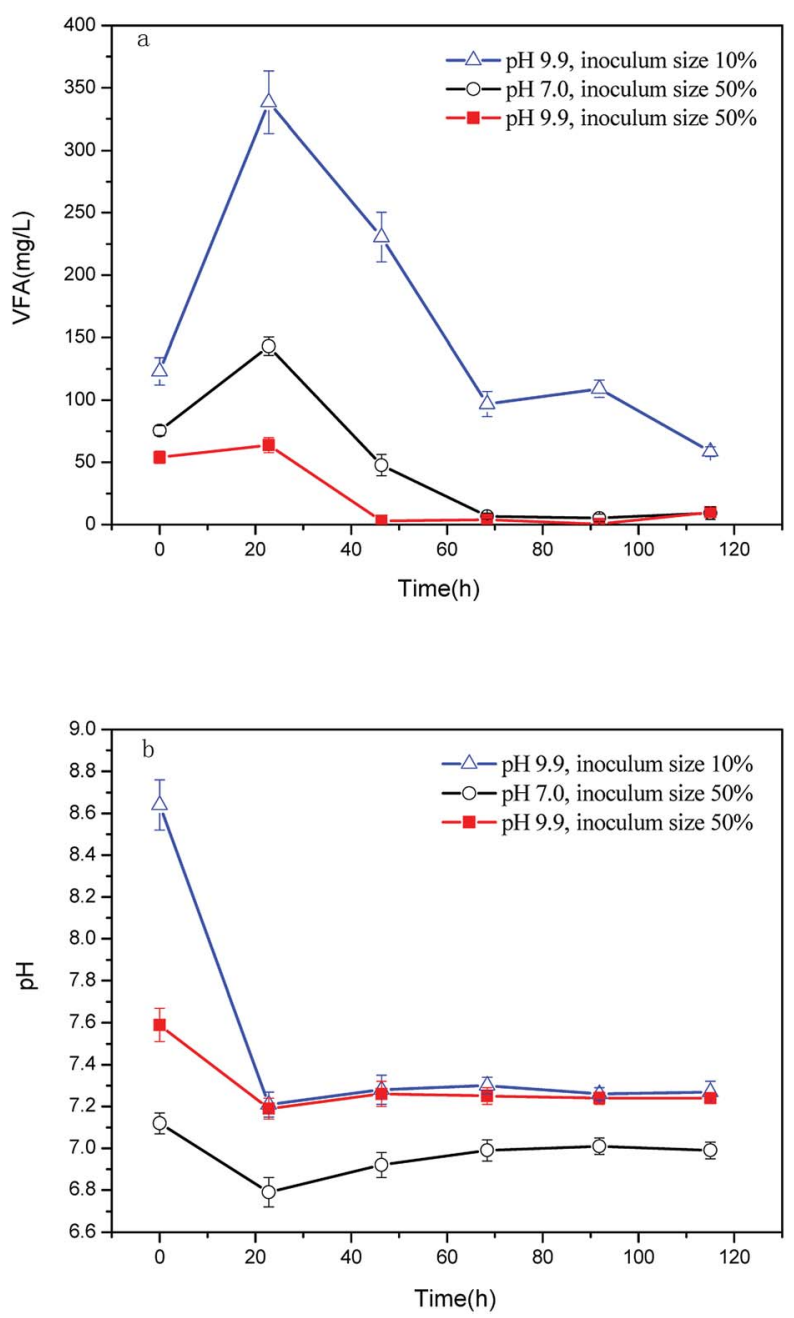

Fig. 5 (a) VFA and (b) $\mathrm{pH}$ changes for anaerobic digestion under different operational conditions. 
(Fig. 5b). All the VFA concentrations were within the range of normal values (200-800 $\mathrm{mg} \mathrm{L}^{-1}$, indexed by acetic acid) for $\mathrm{AD},{ }^{34}$ suggesting a well-run AD. A slight VFA accumulation also occurred at the effluent supernatant $\mathrm{pH}$ of 7.0 and inoculum ratio of $50 \%$, resulting in a change of the neutral $\mathrm{pH}$ to slightly acidic that inhibited the activity of methanogens and delayed VFA degradation. Therefore, an effluent supernatant $\mathrm{pH}$ of 9.9 was preferred for methane production as it eliminated VFA accumulation and maintained the flask $\mathrm{pH}$ at approximately 7.2. This constant $\mathrm{pH}$ benefited the methanogens that were sensitive to environmental changes. Hence, there was high rate of methane production at an effluent supernatant $\mathrm{pH}$ of 9.9 and an inoculum ratio of $50 \%$.

\section{Conclusions}

(1) The optimum operational conditions for TSAHS were alkaline hydrolysis $\mathrm{pH}=12.87$, distilled water volume $=30.00 \mathrm{~mL}$, and sludge sample volume $=35.00 \mathrm{~mL}$. Over $19 \%$ of the organic matter in the low-organic sludge was released into the supernatant under these conditions.

(2) The optimum operational conditions for AD were those in which the supernatant could directly be used for AD (without $\mathrm{pH}$ adjustment) i.e. an inoculum size of $60 \%$ with HRT of $12 \mathrm{~h}$. And these conditions achieved a methane production of $392 \mathrm{~mL}$ $\mathrm{CH}_{4}$ per $\mathrm{g}$ COD.

(3) The process achieved a methane production of $0.26 \mathrm{~m}^{3}$ $\mathrm{CH}_{4}$ per $\mathrm{kg}$ VS that accounted for most of the methane potential in the low-organic sludge and a VS reduction of $43.5 \%$, while the HRT was only $12 \mathrm{~h}$. Therefore, the objective of designing a new process was achieved.

(4) The process mechanism discovered that the sewage sludge possessed considerable alkaline neutralization capacity to maintain a $\mathrm{pH}$ of $9-10$ in the effluent supernatant. This alkalinity eliminated VFA accumulation during AD and maintained the reactor at approximately $\mathrm{pH}$ 7.2, which benefited methane production. It confirmed the feasibility of dissolution of organic matter in the low-organic sludge by strong alkaline hydrolysis for a short digestion time.

\section{Conflicts of interest}

There are no conflicts of interest to declare.

\section{Acknowledgements}

This research was supported by the Major Science and Technology Project of Guangdong Province of China [2016B020240005] and the Natural Science Foundation of Guangdong Province of China [2016A030310317]. The authors are grateful to Dr Weimin Wu (Stanford University) for proof reading of this article.

\section{References}

1 X. Guo, Y. Yin, C. Yang and Z. Dang, Ecotoxicol. Environ. Saf., 2018, 152, 16.
2 H. G. Guo, L. Z. Du, J. F. Liang, Z. J. Yang, G. H. Cui and K. Q. Zhang, BioResources, 2017, 12, 195-210.

3 N. D. Park, S. S. Helle and R. W. Thring, Biomass Bioenergy, 2012, 46, 750-756.

4 B. Jin, J. Niu, J. Dai, N. Li, P. Zhou, J. Niu, J. Zhang, H. Tao, Z. Ma and Z. Zhang, Bioresour. Technol., 2018, 8-16.

5 A. Cesaro and V. Belgiorno, Chem. Eng. J., 2014, 240, 24-37.

6 K. S. Shin and H. Kang, Appl. Biochem. Biotechnol., 2003, 109, 227-239.

7 I. Toreci, K. J. Kennedy and R. L. Droste, Water Res., 2009, 43, 1273-1284.

8 X. Tian, A. P. Trzcinski, L. L. Lin and W. J. Ng, J. Environ. Sci., 2015, 33, 29-38.

9 V. K. Tyagi and S.-L. Lo, Rev. Environ. Sci. Bio/Technol., 2011, 10, 215-242.

10 Y. Yan, H. Chen, W. Xu, Q. He and Q. Zhou, Biochem. Eng. J., 2013, 70, 127-134.

11 X. Wang, X. Duan, J. Chen, K. Fang, L. Feng, Y. Yan and Q. Zhou, Environ. Technol., 2016, 37, 1520-1529.

12 L. Y. Feng, L. Q. Yang, L. X. Zhang, H. L. Chen and J. Chen, Water Sci. Technol., 2013, 68, 1591-1598.

13 D. Bolzonella, P. Pavan, P. Battistoni and F. Cecchi, Process Biochem., 2005, 40, 1453-1460.

$14 \mathrm{~J}$. Hong and X. Li, Waste Manage., 2011, 31, 1364-1371.

15 F. Y. G. Becerra, E. J. Acosta and D. G. Allen, Bioresour. Technol., 2010, 101, 6972-6980.

16 J. Kim, Y. Yu and C. Lee, Bioresour. Technol., 2013, 144, 194201.

17 H. Li, C. Li, W. Liu and S. Zou, Bioresour. Technol., 2012, 123, 189-194.

18 W. Bi, Y. Li and Y. Hu, Bioresour. Technol., 2014, 166, 1-8.

19 Y. Li, Y. Hu, G. Wang, W. Lan, J. Lin, Q. Bi, H. Shen and S. Liang, Chem. Eng. J., 2014, 255, 365-371.

20 Z. Lu, X. Zhou and J. Wu, Chin. J. Environ. Eng., 2011, 5, 11151118.

21 F. S. Wei, Standard methods for the examination of water and wastewater, Ministry of Environmental Protection, Beijing, China, 2002.

22 Y. L. He, Anaerobic wastewater treatment, Chinese Light Industry Press, Beijing, China, 1998.

23 H. Zhu, W. Parker, R. Basnar, A. Proracki, P. Falletta, M. Beland and P. Seto, Int. J. Hydrogen Energy, 2008, 33, 3651-3659.

24 S. Karnchanawong, T. Mongkontep and K. Praphunsri, J. Cleaner Prod., 2017, 146, 14-19.

25 B. Xiao, Q. Dai, X. Yu, P. Yu, S. Zhai, R. Liu, X. Guo, J. Liu and H. Chen, J. Hazard. Mater., 2018, 343, 347-355.

26 E. Alkaya and G. N. Demirer, Renewable Energy, 2011, 36, 971-975.

27 D. Zhang, Y. Chen, Y. Zhao and Z. Ye, Environ. Sci. Technol., 2011, 45, 803-808.

28 C. Park, C. Lee, S. Kim, Y. Chen and H. A. Chase, J. Biosci. Bioeng., 2005, 100, 164-167.

29 A. Tiehm, K. Nickel, M. Zellhorn and U. Neis, Water Res., 2001, 35, 2003-2009.

30 D. Zhang, Y. Chen, Y. Zhao and X. Zhu, Environ. Sci. Technol., 2010, 44, 4802-4808. 
31 J. M. Fernandez, N. Senesi, C. Plaza, G. Brunetti and A. Polo, 33 S. A. Mirbagheri, M. K. Poshtegal and M. S. Parisai, Pedosphere, 2009, 19, 281-291. Desalination, 2010, 256, 70-76.

32 R. Gebauer and B. Eikebrokk, Bioresour. Technol., 2006, 97, 34 J. Q. Zou, Industrial wastewater treatment technology, 2389-2401. Chemical Industry Press, Beijing, China, 2003. 